\title{
Beta Contábil Versus Beta CAPM: Uma Investigação Empírica na Mercado Financeiro Brasileiro
}

\author{
Accountable Beta Versus CAPM Beta: A Empirical Research in the Brazilian \\ Financial Market
}

\author{
Raimundo Nonato Rodrigues \\ Doutor em Contabilidade \\ Felipe Dantas Cassimiro da Silva \\ Mestre em Contabilidade
}

\author{
Jeronymo José Libonati \\ Doutor em Contabilidade \\ Dimmitre Morant Vieira Gonçalves Pereira \\ Mestre em Contabilidade
}

\begin{abstract}
Resumo:
Uma das questões, atualmente discutidas na Moderna Teoria de Finanças diz respeito à avaliação do risco e do retorno no processo de decisão de investimento. Levando-se em conta as premissas desta Teoria, um dos parâmetros de avaliação do risco é através do "beta" extraído do modelo CAPM. No entanto, o desenvolvimento teórico deste modelo está totalmente embasado em uma dinâmica de mercado acionário forte, o que dificulta a sua plena aplicação em mercados com predominância de empresas com Capital Fechado, como o brasileiro. Por outro lado, vem desenvolvendo-se alternativas, na literatura, para esta problemática, e uma delas é o que se convencionou chamar de Beta Contábil, devido a utilização da informação contábil para sua concepção. Diante deste contexto, o artigo em tela teve por objetivo verificar a hipótese da utilização do Beta Contábil em substituição do Beta CAPM para empresas de capital fechado. Para tanto, foi utilizado um estudo empírico, através de prova não-paramétrica Mann-Whitney U, em ações de empresas do setor siderúrgico e metalúrgico extraídos do Banco de Dados da Consultoria Economática, no período de 2001 a 2005. Concluiu-se, por fim, através dos resultados obtidos, que o Beta Contábil substitui significativamente, o Beta CAPM, para a amostra selecionada.
\end{abstract}

Palavras-chaves: Beta contábil; Beta CAPM; Mercado Financeiro Brasileiro.

\begin{abstract}
:
One of the issues currently discussed in the Finance Theory Modern is related with risk assessment and return in decision-making on investment. Considering the assumptions of this theory, one of the parameters of risk assessment is through the "beta" extracted from the CAPM model. However, the theoretical development of this model is fully based on a dynamic of strong stock market, which hinders its full implementation in markets with a predominance of companies with closed capital, as the Brazilian. On the other hand, has been developing alternatives to, in literature, for this problem, and one of them is the termed Accountable Beta, because the use of accounting information for its design. Given this context, this paper aimed. to check the possibility of the use of accountable Beta in place of CAPM Beta for closed capital companies. To that end, we used an empirical study by non-parametric proof Mann-Whitney $U$, in shares of companies in the steel and metallurgical industry pulled out from the Economatica Information Bases, in the period 2001-2005. This study concluded that o Accontable Beta repaces the CAPM Beta, significantly, for tne sample selected.
\end{abstract}

Keywords: Accountable Beta, CAPM Beta, Brazilian Financial Marketing. 


\section{Introdução}

Para determinação da escolha de alternativas em decisões de investimentos muitos são os fatores que influenciam nesse processo. Atualmente uma das questões amplamente discutidas na moderna teoria de finanças diz respeito à avaliação do risco e do retorno dos investimentos.

Quando o foco destes investimentos são ações sabe-se que a determinação de seus rendimentos futuros possui uma boa dose de incerteza, devido a fatores inerentes às empresas emissoras e a própria conjuntura macroeconômica na qual estão inseridos estes ativos. Muitos são os esforços acadêmicos para entender e calcular o retorno na tentativa de diminuir a incerteza no processo de decisão de investimentos desta modalidade. No entanto, como boa parte das estimações navega em um intervalo de probabilidade de ocorrência surge a figura do risco. Atualmente, risco é um termo comumente utilizado, porém seu real conceito é ainda muito discutido. Securato (1993) define risco como sendo a medida de possibilidade de fracasso em relação aos objetivos prefixados. Já Weston e Brigham (2000) consideram o risco como a possibilidade de que algum acontecimento desfavorável venha a ocorrer. Tratando-se de investimentos, risco é relativo à probabilidade de se ganhar menos que o esperado. Já os chineses têm uma percepção mais positiva do risco. Segundo Xei e Wang (2003) a palavra que define risco em chinês é $W e i-J i$, uma combinação das palavras perigo e oportunidade.

De acordo com Silva (2003), até meados da década de 50 não existia uma teoria que estabelecesse um relacionamento entre o risco e o retorno. Através dos trabalhos de Markowitz, no clássico Portfolio Selection (Seleção de Carteiras), publicado em 1952, deu-se início a uma nova abordagem à teoria de finanças, determinando o que ele chamou de "fronteira eficiente" dos ativos de risco em que a maximização dos retornos dos ativos estaria ancorada na premissa de seleção de carteiras, dado um nível de risco. Alguns anos depois, precisamente em 1964, Sharpe, publica o trabalho intitulado Capital asset prices: a theory of market equilibrium under condictions risk, onde foi desenvolvido e simplificado o modelo de Markowitz, sendo conhecimento mundialmente pela denominação: Capital Asset Pricing Model, Arbitrage Pricing Theory (CAPM), onde foi demonstrado haver uma relação linear entre o risco e o retorno da ação de uma empresa ou de uma carteira de investimento.

O modelo de Sharpe está apoiado na premissa que o retorno de uma carteira diversificada está apenas sobre o efeito do risco sistêmico, ou seja, a diversificação da carteira já elimina o risco associados aos ativos pertencentes a carteira, mas não elimina o risco associado ao mercado. Logo, o melhor parâmetro, segundo esta teoria, que espelha todos os fatores de risco associados ao mercado seria a taxa de retorno do mercado (por exemplo, os índices de Bolsas de Valores). Portanto, o modelo prediz uma relação linear entre o retorno de uma portifólio de ativos e o retorno do mercado, onde o coeficiente angular (beta) mede a sensibilidade entre estas duas variáveis, isto é, o risco da carteira de ativos.

Tal contexto teórico tem seu fundamento nas Hipóteses de Mercado Eficiente, onde o comportamento dos investidores é avesso ao risco, tendo em vista que todos tem acesso, sem custo, a todas as informações do mercado e tentarão ao máximo minimizar esse risco, em favor da maximização dos retornos (posicionamento dito racional nas Finanças Moderna). No entanto, vale salientar, que as oscilações de uma ação possam depender de diversos fatores, como defendem Cupertino e Oliveira (2000), tais como perspectiva de geração de fluxos futuros de caixa, aquecimento no nível de atividades de um determinado segmento de negócio, entre outros.

Por outro lado, o modelo $C A P M$ foi desenvolvido em um ambiente de negociações de ações em bolsa de valores, isto é, com empresas de capital aberto, onde é levado em consideração, por exemplo, o risco de mercado (beta) em sua metodologia.

Já no Brasil, dado o panorama do mercado acionário, que ainda se encontra em desenvolvimento, diferentemente dos grandes centros financeiros como o norte americano e o 
europeu, a utilização da metodologia CAPM fica um pouco prejudicada. Tendo em vista isto, vem se desenvolvendo na literatura de Finanças [(BEAVER e MANEGOLD, 1975); (KLOECKNER, 1993); (DAMODARAM， 1997); (BREALEY e MYERS, 1998); (COPELAND, KOLLER E MURRIN, 2002); (FAMÁ E RIBEIRO NETO, 2001); (CARDOSO E MARTINS, 2004)] mecanismos alternativos que dêem aproximações mais seguras para estimação do risco desta classe de ativos. E um destes mecanismos é o que se convencionou chamar beta contábil, "[...] pois no lugar de dados obtidos do mercado acionário, o investidor utiliza dados provenientes das demonstrações contábeis, sendo utilizadas médias e variâncias de índices [...] como estimação do risco da empresa". (CARDOSO E MARTINS, 2004, p. 93)

Ainda, em ambientes como o Brasil, onde a grande maioria das empresas é de Capital Fechado, Cardoso e Martins (2004) afirmam que o beta contábil pode ser um substituto do beta de mercado. Ou ainda como afirmam Brealey e Myers (1998, p. 289) "[...] o que realmente interessa é a intensidade da relação entre e os lucros de todos os ativos reais. [...] e podemos quantificá-la através do beta contabilístico [...]. Este é igual ao beta real, [...]". Com base nestas afirmações, bem como em todo o contexto descrito anteriormente, o presente artigo tem como problemática o seguinte questionamento: $O$ beta contábil pode ser um substituto significativo do beta de mercado do modelo CAPM?

\section{Principais Marcos Teóricos}

\subsection{Risco e Retorno}

Os principais conceitos da Moderna Teoria de Finanças ${ }^{1}$, como a Teoria de Portifólio proposta por Markowitz (1952), Modelo de Precificação de Ativos Financeiros (CAPM) desenvolvido inicialmente por Sharpe (1964) e a Hipótese de Eficiência de Mercados de capitais (HEM) proposta por Fama (1970), estão baseados na premissa que o investidor é racional, avesso ao risco e que utiliza a curva de utilidade para maximizar seu bem estar. As preferências do investidor racional com relação às taxas de risco e retorno podem ser representadas através de uma Curva de Indiferença, conforme a figura abaixo:

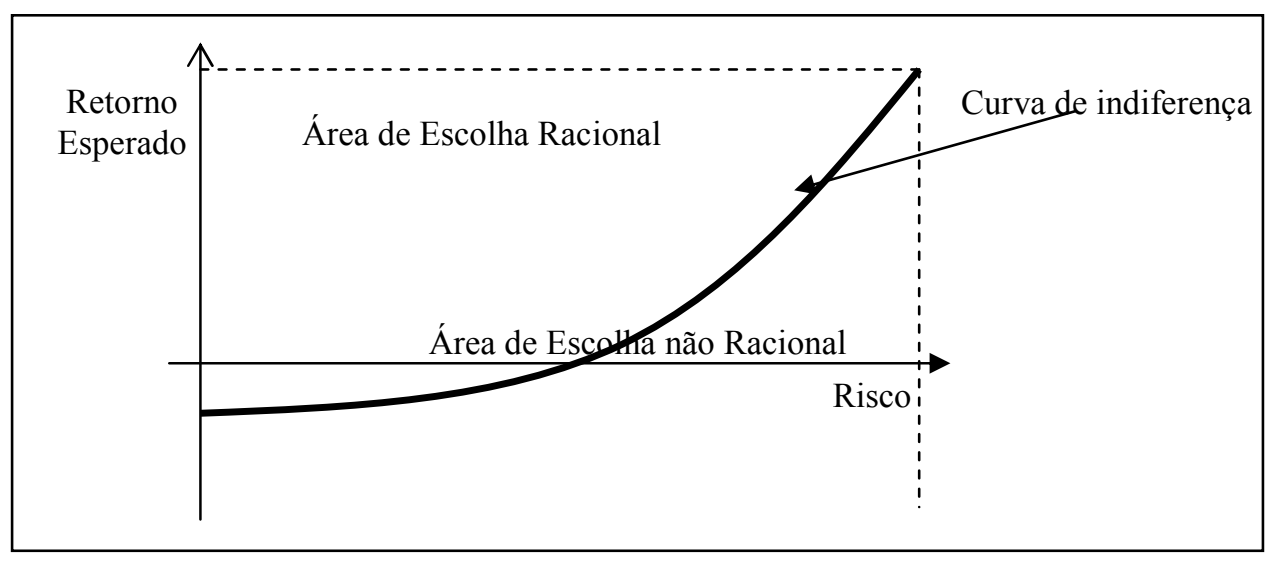

Figura 01 - Curva de Indiferença

Fonte: (Adaptado de Ross, Westerfield e Jaffe, 1995)

Nessa representação da Curva de Indiferença, observa-se que para qualquer ponto sobre a curva o investidor maximiza sua satisfação associada a diferentes níveis de risco e retorno. Nela pode-se observar que para o mesmo nível de risco o investidor racional deve optar pelas alternativas que proporcionam maiores retornos. Pois, como afirma Assaf Neto (1999, p.236):

A regra básica de uma decisão racional é selecionar ativos que apresentam o menor risco e o maior retorno esperado. Para um mesmo nível de risco um investidor racional seleciona o ativo de maior retorno esperado. 
Segundo a Teoria da Seleção de Carteiras de Markowitz (1952) o investidor, na composição de um portifólio, deve identificar a melhor alternativa possível com relação à combinação entre os fatores risco e retorno. Ainda segundo essa teoria o investidor através da associação entre dois ou mais ativos que apresentem correlações negativas ou perfeitamente negativas pode obter um grau de risco menor do que àquele que seria obtido pelos ativos isoladamente.

Para Sanvicente (1997, p.60) "passa-se de uma situação de incerteza para uma situação de risco quando se pode fazer estimativas das probabilidades de ocorrência de determinados eventos". No entendimento de Weston e Brigham (2000, p.155) o risco "(...) refere-se à possibilidade de que algum acontecimento desfavorável venha a acontecer". Para Ross, Westerfield e Jaffe (1995, p. 183) "Os investidores só assumirão posições num título com risco se o retorno for suficientemente elevado para compensar o risco".

Gitman (1997) define o risco como a probabilidade de se auferir um prejuízo financeiro decorrente da variação dos retornos ${ }^{2}$ de determinado ativo. Para o mesmo autor o desvio padrão $(\square)$ é o indicador estatístico mais comum para evidenciar o risco de um ativo, pois mede a dispersão em torno do retorno médio esperado. Logo, quanto maior a dispersão (Desvio-Padrão) em relação ao Retorno Esperado (Média) maior será o risco, como demonstra a figura abaixo:

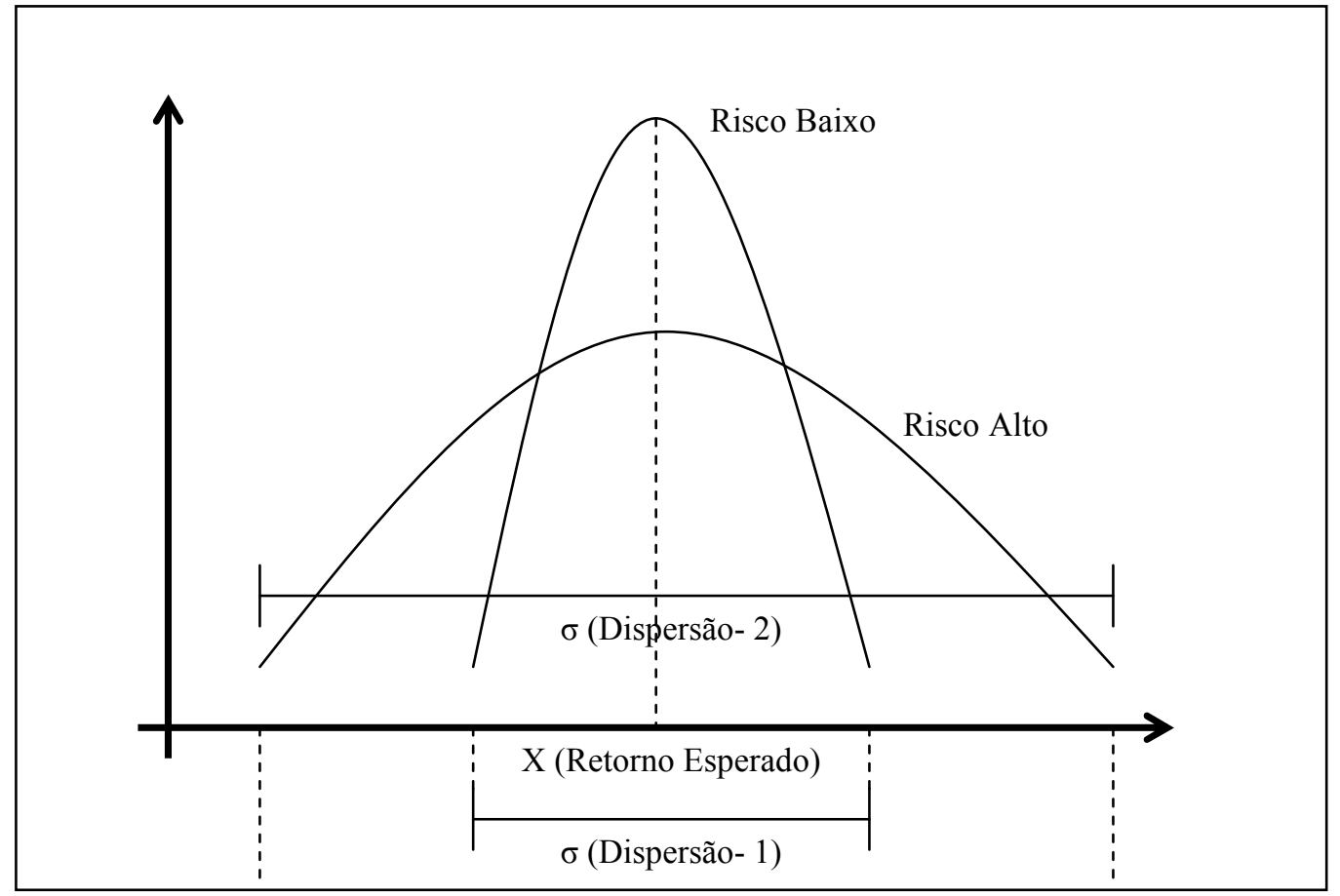

Figura 02 - Representação gráfica do risco em uma distribuição de probabilidade (Fonte: Adaptado de Assaf Neto, 1999)

\subsection{Relação entre o risco e o retorno no modelo CAPM}

O Modelo de Precificação de Ativos Financeiros (CAPM) considera que o risco total de um título é representado pela soma do Risco não-diversificável (ou sistêmico) com o Risco diversificável (GITMAN, 1997). O Risco não-diversificável é o mesmo para todos os ativos negociados no mercado, sendo determinado por eventos de natureza política, econômica e social. O Risco diversificável, por sua vez, está associado às características do ativo em si, logo, pode ser total ou parcialmente eliminado através da diversificação de ativos, segundo a Teoria da Seleção de Carteiras (MARKOWITZ, 1952). Ou seja, o importante é a contribuição de cada título ao risco total do portifólio e não o seu risco individual. Desta forma, pode-se afirmar que o risco total é: 
Diante disto, o Modelo CAPM pressupõe que os investidores racionais estarão expostos apenas ao Risco não-diversificável, uma vez que procurarão diversificar seu portifólio diminuindo ou eliminando o risco diversificável. No entanto, a diversificação não elimina o risco sistêmico, mesmo com a adição de mais títulos à carteira, como demonstra a figura abaixo:

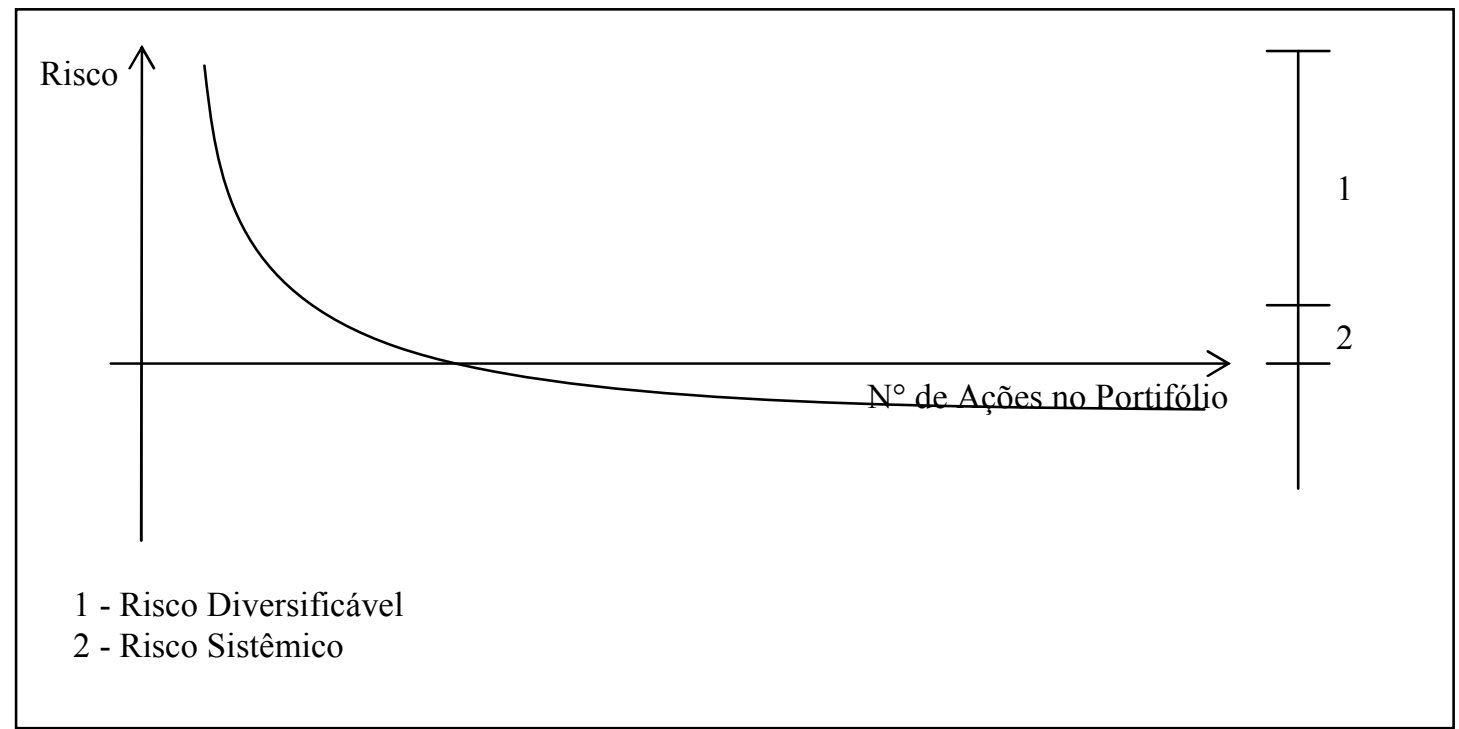

Figura 03 - Representação Gráfica da Redução do Risco com a Diversificação (Fonte: Adaptado de Gitman, 1997)

Nestas condições o retorno esperado de um portifólio é uma média ponderada dos retornos esperados dos títulos que compõem a carteira, definido por:

$E\left(R_{p}\right)=E\left(\sum_{i=1}^{n} W_{i} R_{i}\right)=\sum_{i=1}^{n} W_{i} E\left(R_{i}\right)$

Onde,

$\mathrm{E}\left(\mathrm{R}_{\mathrm{p}}\right)$ - Retorno Esperado do Portifólio;

$\mathrm{W}_{\mathrm{i}}$ - Participação do título no Portifólio;

$\mathrm{E}\left(\mathrm{R}_{\mathrm{i}}\right)$ - Retorno Esperado do Título.

E sua variância definido por:

$\operatorname{VAR}\left(R_{p}\right)=\sum_{i=1}^{n} \sum_{j=1}^{n} W_{i} W_{j} \operatorname{COV}\left(R_{i}, R_{j}\right)$

Onde,

$\mathrm{W}_{\mathrm{i}}, \mathrm{W}_{\mathrm{j}}$ - Participação dos títulos na Carteira;

$\operatorname{COV}\left(\mathrm{R}_{\mathrm{i}}, \mathrm{R}_{\mathrm{j}}\right)$ - Covariância entro os Retornos de dois títulos, definido por:

$\operatorname{COV}\left(R_{i}, R_{j}\right)=\frac{\sum_{k=1}^{n}\left(R_{i}-\overline{R_{i}}\right) \cdot\left(R_{j}-\overline{R_{j}}\right)}{n}$

Na equação do Modelo (CAPM) o Risco não-diversificável é representado pelo beta ( $\beta$ ) e está relacionado de forma linear e positiva ao retorno esperado (ROSS, WESTERFIELD E JAFFE, 1995). Dessa forma, os investidores determinam a estrutura da carteira de modo a maximizar a utilidade, tomando como referência um ativo livre de risco. Assim, o excesso de 
rendimento esperado de um ativo em relação a um ativo livre de risco é proporcional ao excesso de rendimento esperado do portifólio em seu conjunto em relação ao retorno livre de risco.

$$
E\left(R_{i}\right)-R_{f}=\beta_{i}\left\lfloor E\left(R_{m}\right)-R_{f}\right\rfloor
$$

Onde,

$E\left(R_{i}\right)-R_{f}-$ Retorno excedente esperado de um ativo em risco;

$\mathrm{R}_{\mathrm{f}}-$ Retorno Livre de risco;

$\beta_{i}-$ Beta do ativo (Risco sistêmico);

$\left[E\left(R_{m}\right)-R_{f}\right]$ - Prêmio pelo risco, ou seja, a diferença entre o retorno esperado da carteira de mercado e o retorno livre de risco.

O $\beta_{\text {i }}$ pode ser obtido pela seguinte dotação matemática, segundo Assaf Neto (1999) $\square$

$$
\beta_{i}=\frac{\operatorname{COV}\left(R_{i}, R_{m}\right)}{\sigma^{2}\left(R_{m}\right)}
$$

Onde,

COV $\left(\mathrm{R}_{\mathrm{i}}, \mathrm{R}_{\mathrm{m}}\right)$ - Covariância entre o Retorno do Título e o Retorno do Mercado; $\sigma^{2}\left(R_{m}\right)$ - Variância do Retorno do Mercado.

A estimação econométrica da equação (3) é usualmente feita pelo modelo linear:

$$
r_{i}=\alpha_{i}+\beta_{i} \cdot r_{m}+e_{i}
$$

Onde,

$\mathrm{r}_{\mathrm{i}}$ - Taxa de retorno do ativo que excede o ativo livre de risco;

$\alpha_{\mathrm{i}}$ - Taxa de retorno esperado do i-ésimo ativo. Será igual ao ativo livre de risco, caso o retorno de mercado seja nulo;

$\beta_{\mathrm{i}}$ - Medida de sensibilidade (coeficiente angular) do prêmio de risco do i-ésimo ativo em relação ao prêmio de risco do mercado;

$\mathrm{r}_{\mathrm{m}}$ - Prêmio de risco do mercado, medido por um de seus índices;

$e_{i}-$ Erro (perturbação estocástica).

Para Weston e Brigham (2000, p. 175) "a tendência de uma ação mover-se com o mercado é refletida em seu coeficiente beta $(\boldsymbol{\beta})$ ". Ainda para os mesmos autores uma ação com risco mediano tende a valorizações e desvalorizações similares às do mercado geral (definido por algum índice como Standards Pool 500, Dow Jones, Bovespa e outros) e tem seu beta $(\boldsymbol{\beta})=1$.

Por exemplo: (a) se o beta ( $\boldsymbol{\beta})$ de determinado ativo é 1(um) e o mercado geral (representado pelo índice Bovespa) tem alta de 5\%, o mesmo ativo se valorizará 5\%; (b) se o beta ( $\boldsymbol{\beta})$ do ativo é 2 (dois) a valorização do ativo será de 10\%. Em contrapartida, no caso de do índice Bovespa apresentar uma queda de $10 \%$ a desvalorização do ativo na situação (a) será de $10 \%$ e na situação (b) a desvalorização será de $\mathbf{2 0 \%}$.

Portanto, pode-se afirmar que para os valores do beta $(\boldsymbol{\beta})$ maiores que 1 os ativos são mais arriscados que os ativos com valor do beta $(\boldsymbol{\beta})$ menor que 1 , em contrapartida os retornos esperados para os betas $(\boldsymbol{\beta})>1$ são maiores.

Outra propriedade importante do CAPM é que a medida de risco para ativos individuais é linearmente aditiva quando os ativos são combinados para constituir um 
portifólio. Assim, se cada ativo participar $\mathrm{W}_{\mathrm{i}}$ no valor total da carteira, com risco sistemático $\beta_{\mathrm{i}}$, então o beta do portifólio resultante será, conforme Assaf Neto (1999):

$\beta_{p}=\sum_{i=1}^{n} W_{i} \beta_{i}$

Onde,

$\beta_{\mathrm{p}}$ - Risco Sistemático do Portifólio;

$\mathrm{W}_{\mathrm{i}} \beta_{\mathrm{i}}$ - Produto da participação do i-ésimo ativo no portifólio e seu respectivo risco sistemático individual.

Esta metodologia supra mencionada, evita o problema da programação quadrática para encontrar o conjunto eficiente do portifólio.

O modelo CAPM requer que, em equilíbrio, o portifólio de mercado seja eficiente. Em teoria, quando todos os investidores têm expectativas homogêneas o mercado é eficiente. Consequentemente é importante ressaltar que o CAPM é desenvolvido, como dito anteriormente, sob hipótese de um mercado extremamente bem comportado e transparente, exigindo assim cautela na interpretação do modelo (COPELAND, 1993).

\subsection{O CAPM e o Beta Contábil}

Para Cardoso e Martins (2004), existe uma relação entre os retornos dos ativos obtidos pelo CAPM e as informações contábeis. Segundo os mesmos autores, a Contabilidade fornece dados passados sobre fluxos de caixa, dividendos, lucros e outros, possibilitando assim a estimação de dados futuros sobre essas variáveis, com destaque para o lucro, por este ser utilizado como uma evidência indireta dos fluxos de caixas (determinantes para avaliação dos ativos no modelo CAPM).

Outro ponto levantado por Cardoso e Martins (2004) diz respeito à capacidade que as informações contábeis divulgadas têm de alterar ou não as expectativas do mercado com relação à avaliação das empresas, enquanto o (CAPM) representa o valor presente dos fluxos de caixa futuros, uma alteração nesse valor decorrente de uma nova informação (divulgação de informações contábeis) aferida pelo próprio modelo permite inferir que o modelo (CAPM) aliado à informações contábeis podem, em conjunto, representar o impacto da divulgação de informações contábeis no valor dos ativos.

A hipótese de mercado eficiente e o CAPM significam que a nova informação relevante exercerá um efeito imediato sobre o preço de um título, seja alterando expectativas à respeito do retorno médio de um título, seja alterando expectativas quanto ao seu beta. (HENDRIKSEN E VANBREDA, 1999, p. 184).

No modelo (CAPM) o beta $(\boldsymbol{\beta})$, como visto anteriormente, representa o risco associado a carteira de títulos sendo, também, representativo da sensibilidade dos retornos esperados em relação às oscilações do mercado. Em ambientes em que o mercado acionário se encontra em fase de desenvolvimento, caso brasileiro, o beta contábil pode servir de parâmetro em substituição ao beta ( $\boldsymbol{\beta})$ do mercado. (CARDOSO E MARTINS, 2004).

Reforçando esta idéia, Damoram (1997), Kloeckner (1993) e Copeland, Koller e Murrin (2002), argumentam que para empresas que não negociam títulos mobiliários em bolsas, a definição objetiva do Custo de Capital Próprio torna-se mais complexa. Desta forma, dentre outras alternativas, sugere que este tipo de empresa possa ser avaliado através da estimação de taxas de desconto com base em betas contábeis. Ou seja, um beta contábil é estimado a partir dos lucros e não dos retornos. Logo, os lucros periódicos da empresa são regredidos contra os lucros agregados do setor ou índice que melhor represente o setor onde a empresa está inserida. 
De forma mais objetiva, Cardoso e Martins (2004) sugerem que o beta contábil seja obtido a partir da equação da reta de regressão entre ROI-ajustado (LAJIR/Ativo total) de uma empresa e o ROI-ajustado (LAJIR/Ativo total) do setor de mercado no qual está inserid a empresa, acreditando que o lucro antes do imposto de renda e do resultado financeiro (LAJIR ou EBIT) utilizado em detrimento do lucro líquido (LL), minimize as distorções causadas pelas alterações no regime de tributação ao longo do tempo e da estrutura de financiamento de cada empresa.

Justifica-se a utilização deste indicador de rentabilidade, considerando que o investidor, ao assumir riscos, procura se apoiar em medidas de eficiência e rentabilidade, muito embora, não sejam apenas estes que nortearão o suprimento da incerteza, porém há de se considerar sua importância, pois o ROA-ajustado determinará um índice que medirá a capacidade de geração de lucros a partir dos seus ativos.

Portanto, pode-se definir o beta contábil através da seguinte dotação matemática (mudando as variáveis da equação 4):

$\beta_{c}=\frac{\operatorname{COV}\left(R_{0}, \mathrm{ROI}_{m}\right)}{\sigma^{2}\left(R_{\mathrm{I}}\right)}$

Onde,

$\beta_{\mathrm{c}}-$ Beta Contábil (Risco);

$\mathrm{ROI}_{\mathrm{e}}, \mathrm{ROI}_{\mathrm{m}}$ - Retorno sobre o Investimento ajustado da empresa e do mercado, respectivamente.

COV $\left(\mathrm{ROI}_{\mathrm{e}}, \mathrm{ROI}_{\mathrm{m}}\right)$ - Covariância entre o ROI-ajustado da empresa e o ROI-ajustado do mercado;

$\sigma^{2}\left(\mathrm{ROI}_{\mathrm{m}}\right)-$ Variância do ROI-ajustado do mercado.

\section{Procedimento Metodológico}

Esta pesquisa está inserida em uma tipologia de pesquisa empírica, de abordagem dedutiva, com a utilização de dados contábeis e de mercado de empresas que cotam ações na Bolsa de Valores no Brasil (BOVESPA).

Para tanto, escolheu-se o setor de Metalurgia e Siderurgia, entendendo ser um dos setores mais consolidados em termos de mercado de capitais no Brasil e pela disponibilização dos dados, se caracterizando, desta forma, como uma amostra por conveniência.

A princípio foi extraída do Banco de Dados Economática uma população de 56 tipos de ações (entre Ordinárias e preferenciais) de 43 empresas do setor em tela, haja vista que uma empresa pode ter mais um tipo de ação cotada em bolsa de valores. Tendo em vista a necessidade de ter apenas um tipo de ativo (ação) por empresa, foram selecionadas as ações com maior movimentação de negociação. Com isso, a amostra se constituiu em 43 ações (o mesmo número de empresa). Em um terceiro momento, devido a falta ou inconsistência de dados, a amostra caiu para 20 ações (correspondendo a 20 empresas), ou seja, aproximadamente $46 \%$ da amostra original. O Banco de Dados Economática já fornece os betas (pela metodologia CAPM) das ações cotas na BOVESPA, com isso, não foi preciso calcular os 20 betas-CAPM das 20 ações da amostra selecionada.

Como a Consultoria Economática considera os últimos 60 meses para fins de cálculo do beta (pela metodologia CAPM) e o ano de referência para a análise foi 2005, utilizou-se o mesmo espaço temporal para o cálculo do Beta Contábil, ou seja, os últimos 5 anos de dados trimestrais contábeis (2001-2005).

O cálculo do Beta Contábil seguiu a metodologia proposta por Cardoso e Martins (2004), tendo com parâmetro de retorno (ROI-ajustado) a relação entre o LAJIR (Lucro Antes do Juros e do IR) e os Ativos Totais de cada empresa estudada. Com isso, foram rodadas, com o auxílio do software SPSS 13 (Statistical Package for the Social Sciences), 20 regressões de 
forma a identificar 20 betas (coeficientes de inclinação da Regressão) correspondentes as 20 empresas da amostra, para serem comparadas com os 20 betas-CAPM extraídos do Economática, conforme o modelo abaixo.

$$
R O I_{m}=\beta_{1}+\beta_{2} \cdot R O I_{e}+e
$$

Onde,

$R O I_{m}$ - Retorno sobre ativos ajustado do setor de atuação;

$\beta_{1}$ e $\beta_{2}$ - Parâmetros regressivos;

$R O I_{e}-$ Retorno sobre ativos ajustado do empresa em estudo;

$e$-Perturbação estocástica do modelo.

Como a amostra é pequena e os dados não se distribuem normalmente conforme os testes de normalidade de Shapiro-Wilk e de Kolmogorov-Smirov disponibilizado no SPSS e recomendado por Hair et al. (2005), optou-se pela utilização da prova não paramétrica U de Mann-Whitney, que é uma alternativa útil à prova paramétrica $t$ e permite saber se duas amostras independentes provêm da mesma população [(SIEGEL, 1979); (STEVENSON, 1981); (MARTINS, 2002); (PEREIRA2003)].

\begin{tabular}{lcrrrrr}
\hline \hline & \multicolumn{4}{c}{ Kolmogorov-Smirnov } & \multicolumn{3}{c}{ Shapiro-Wilk } \\
\cline { 2 - 7 } & Statistic & df & Sig. & Statistic & df & \multicolumn{2}{c}{ Sig. } \\
\hline Beta CAPM &, 164 & 20 &, 000 &, 878 & 20 &, 000 \\
Beta Contábil &, 188 & 20 &, 000 &, 938 & 20 &, 003 \\
\hline \hline
\end{tabular}

Tabela 01 - Teste de Normalidade das Variáveis Explicativas

Fonte: Output do SPSS

Assim, foram testadas as seguintes hipóteses, ao nível de significância de 5\%:

$\mathbf{H}_{0}$ : Não existe diferença significativa entre o Beta Contábil e o Beta CAPM na amostra selecionada;

$\mathbf{H}_{1}$ : Existe diferença significativa entre o Beta Contábil e o Beta CAPM na amostra selecionada;

\section{Análise dos Dados}

A amostra se caracteriza como representativa do setor em termos quantitativos como referenciado no proceder metodológico, em torno de $46 \%$. Isto se confirma quando se visualiza a participação da amostra em termos de participação no setor no mercado, respondendo por $83 \%$ do faturamento bruto total das empresas do setor que operam em mercado acionário aberto, como visualizado no gráfico abaixo.

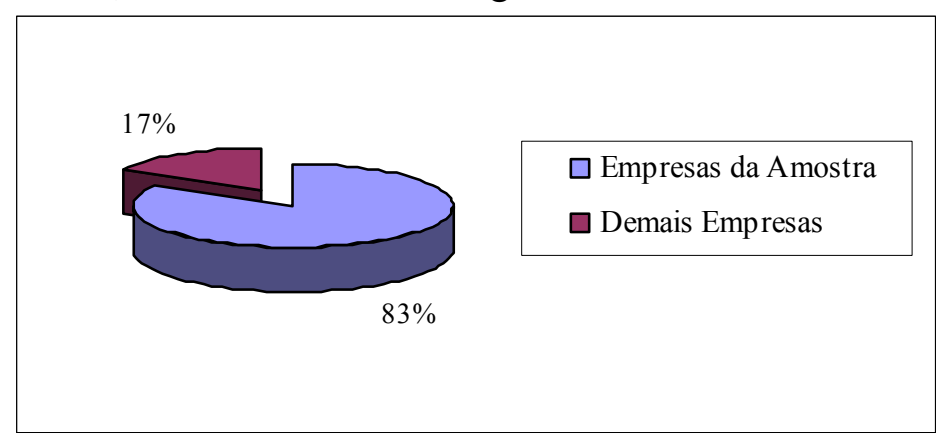

Gráfico 1 - Relação Percentual da Participação das empresas da Amostra no Faturamento Total do Setor (2005) 
A princípio, o resultado das regressões mostra, graficamente, certa conformidade visual entre os dois tipos de beta (CAPM e o Contábil), sendo verificado apenas dois picos divergentes entre os dados, um mais gritante (empresa 4) e outro mais suave (empresa 12), conforme o gráfico abaixo.

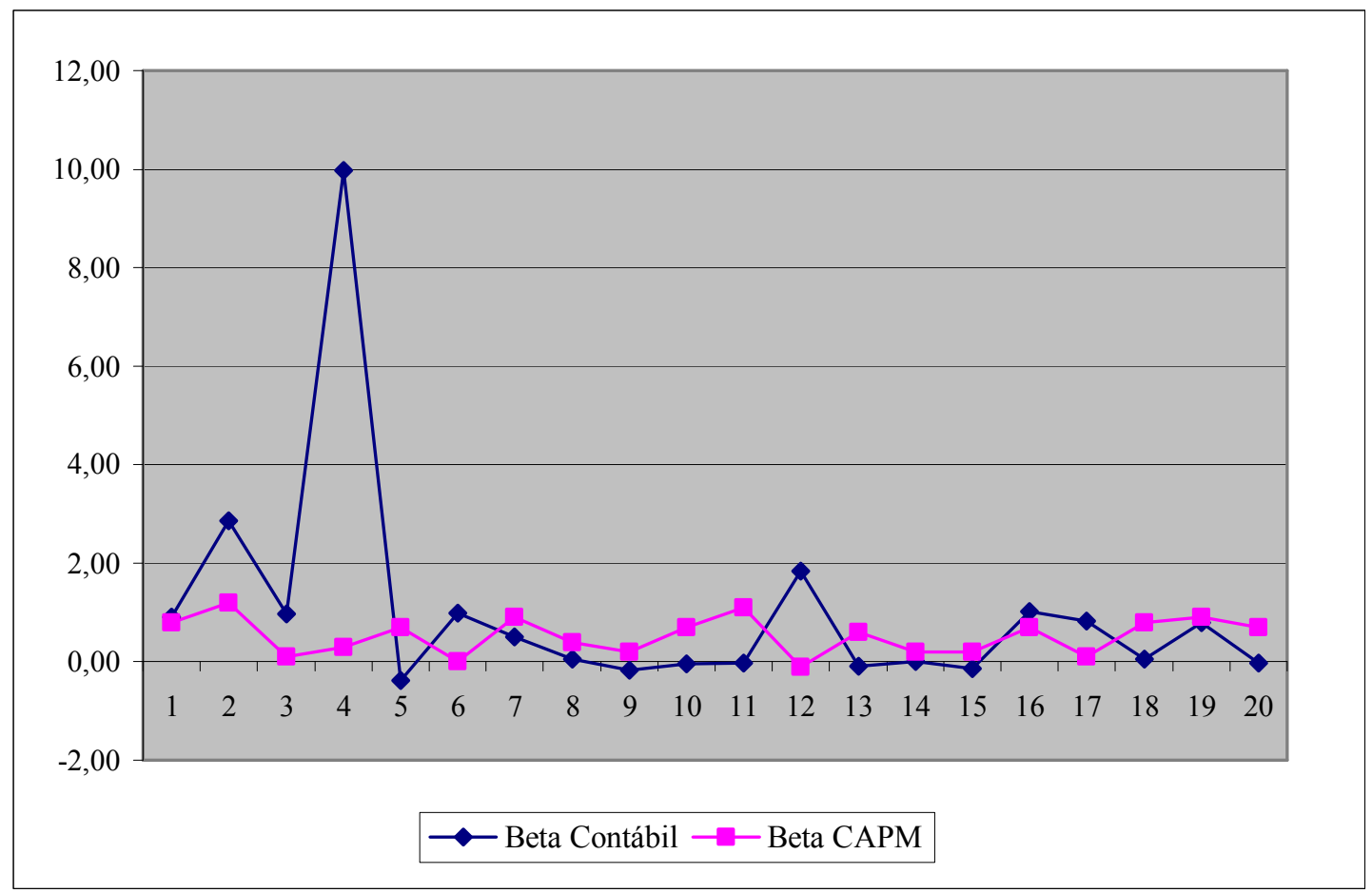

Gráfico 2 - Representação Relacional dos Betas das 20 empresas Estudadas

No entanto, não se pode afirmar com segurança que o Beta Contábil é um bom substituto do Beta CAPM apenas com a análise gráfica dos dados. Portanto, como proposto anteriormente, foi feito um teste estatístico não paramétrico para assegurar as considerações a serem feitas sobre uma possível substituição do beta CAPM pelo Beta Contábil.

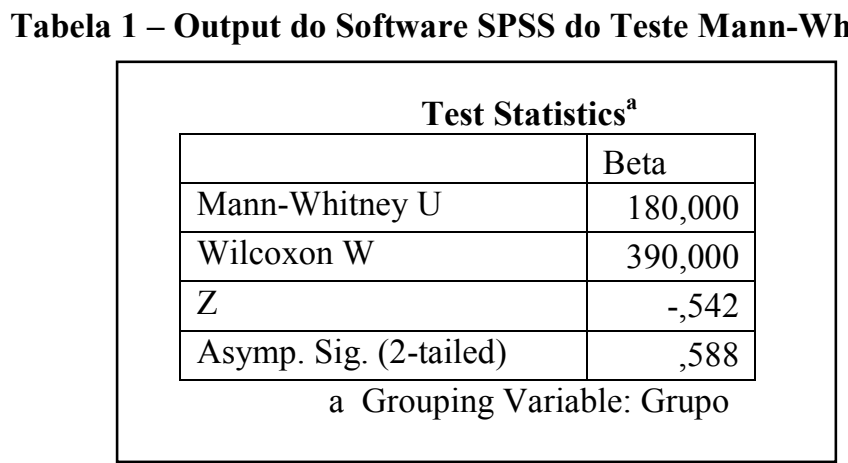

A tabela 01, acima, demonstra o resultado do teste não paramétrico $U$ de MannWhitney (retirado do software SPSS). O valor obtido para um teste bi-caudal (Asymp. Sig.), confirma que a hipótese de nulidade não pode ser rejeitada, considerando-se um nível de significância de 5\%, indicando que as duas amostras (Beta Contábil e o Beta CAPM) dos setores estudados não diferem estatisticamente.

\section{Considerações Finais e Limitações da Pesquisa}

Por se tratar de um tema ainda não muito estudado no país, o beta contabilístico provoca ainda controvérsias. Levando-se em conta, toda a crítica feita nos últimos anos ao 
beta original e a hipótese de Mercado Eficiente, os resultados desta pesquisa servirão como incentivo para futuros estudos mais profundos e robustos. Apesar das limitações, no tocante ao tamanho da amostra e às generalizações, a investigação comprova, empiricamente, a teoria levantada em Damodaram (1997), brealey e Myers (1998), Copeland, Koller e Murrin (2002), e Cardoso e Martins (2004), que o Beta Contábil é um bom substituto o Beta CAPM, na amostra selecionada. Outra contribuição dos achados é o reforço científico e preditivo a teoria, a partir do momento que dá continuidade a trabalhos empíricos já desenvolvidos na temática, como Beaver e Manegold (1975), Kloeckner (1993) e Famá e Ribeiro Neto (2001).

Do ponto de vista social, a relevância deste trabalho converge à necessidade da aplicabilidade prática desta teoria no trato com investimentos em condições de incerteza em empresas de capital fechado no Brasil, não só na área privada como na pública, tendo em vista as recentes privatizações e a necessidade de se valorar empresas para diversos fins.

\section{Referências}

ASSAF NETO, A. Mercado financeiro. São Paulo: Editora Atlas, 1999.

BEAVER e MANEGOLD . The Association Between Market-Determined and Accouting Determined Measures of Systematic Risk: Some Further Evidence. Journal of Financial and Quantitative Analysis, p. 139-202, 1975.

BREALEY, R. A. e MYERS S. C. Princípios de Finanças Empresariais. 5a. edição. São Paulo: Mc Graw Hill, 1998.

BROOKS, C.. Introductory Econometrics for Finance. New York: Cambridge, 2002.

CARDOSO, R. L.; MARTINS, V. A.. Hipótese de Mercado Eficinete e Modelo de Precificação de Ativos Financeiros. In: IUDÍCIBUS, S.; LOPES, A. B.. Teoria Avançada da Contabilidade. São Paulo: Atlas, 2004.

COPELAND, T. E.. Optimal Portifolio From Simple Ranking Devises. The journal of Portifolio Management. Vol. 4, n. 3, p. 15-25, spring 1993.

COPELAND, T.; KOLLER,T.; MURRIN, J.. Avaliação de empresas - valuation. São Paulo: Pearson Education, 2002.

DAMODARAM, A.. Avaliação de Investimentos. Rio de Janeiro: Qualitymark, 1997. FAMÁ, E. F. Efficient Capital Markets: a review of theory and empirical work. Jornal of Finance, Chicago: American Finance Association, p. 383-417, may 1970.

FAMÁ, R.; RIBEIRO NETO, R. M.. Beta Contabilístico - Uma aplicação no mercado financeiro brasileiro. Anais... V SEMEAD. São Paulo, Junho/2001.

GARRISON, R. Y.; NORREEN, E. W. Contabilidade Gerencial. Rio de Janeiro: LTC, 2001.

GITMAN, L. J. Princípios de administração financeira. $7^{\mathrm{a}}$ ed. São Paulo: Harbra, 1997. HAUGEN, R.A. The Inefficient Stock Market: what pays off and why. USA: Prentice Hall, 1999.

HENDRIKSEN, E. S.; BREDA, M. F. V.. Teoria da contabilidade. São Paulo: Atlas, 1999. HAIR, Joseph F.; ANDERSON, Rolph E.; TATHAM, Ronald L.; BLACK, William C.. Análise Multivariada de Dados. Porto Alegre: Bookman, 2005. Tradução da $5^{\circ}$ Edição Americana por Adonai Schlup Sant'Anna e Anselmo Chaves Neto.

KLOECKNER, G. O. Beta Contábil: Uma Medida Alternativa de Risco Sistemático. Anais... $17^{\circ}$ ENANPAD, 1993, Salvador.

MARKOWITZ, H. Portifólio Selection. Jornal of Finance, Chicago: American Finance Association, p. 77-91, march 1952.

MARTINS, Gilberto de Andrade. Estatística Geral e Aplicada. São Paulo: Atlas, 2002. PEREIRA, Alexandre. SPSS - Guia Prático de Utilização - Análise de Dados para Ciências Sociais e Psicologia. 4ªdição Revista e Atualizada. Portugal: Silabo, 2003. 
ROSS, S.A.WESTERFIELD, R.W. JAFFE, J.F. Administração financeira. São Paulo: Editora Atlas, 1995.

SANVICENTE, A.Z. Administração financeira. $3^{\text {a }}$ ed. São Paulo: Editora Atlas, 1987.

SECURATO, José. R. Decisões financeiras em condições de risco. São Paulo: Atlas, 1993.

SHARP, W. F. Capital Asset Prices: A Theory of Market Equilibrium under Conditions of

Risk. Jornal of Finance, Chicago: American Finance Association, v.XIX, n.3, p.425-442,

Sept. 1964.

SIEGEL, Sidney. Estatística Não-Paramétrica - para ciências do comportamento. São Paulo: McGraw - Hill do Brasil, 1979.

SILVA, Marco Aurélio Vallim Reis da. Uma análise empírica da utilização do índice beta do modelo de precificação de ativos (capital asset pricing model - CAPM) como medida de risco no mercado acionário brasileiro. Revista de Ciências Humanas. Universidade de Taubaté-SP. Volume 10, $\mathrm{n}^{\mathrm{o}} .1$ (jun./dez. - 2004).

STEVESON, W. J.. Estatistica Aplicada a Administração. São Paulo: Haper \& Row do Brasil, 1981.

WESTON, J. F. BRIGHAM, E.F. Fundamentos de administração financeira.10a ed. São Paulo: Makron Books, 2000.

XIE, Xiao-Fei; WANG, X.T. Risk Perception and Risky Choice: Situational, Informational, and Dispositional Effects. Asian Journal of Social Psychology, v.6, p. 117-132, 2003.

\section{Notas de Final de Texto}

(1) Haugen (1999) afirma, através de indícios empíricos, que nem sempre os mercados são eficientes, seja pela assimetria de informação, ou pelas diferentes percepções de risco na tomada de decisão pelos investidores (Finanças Comportamentais), ou até mesmo por estes não usarem o mesmo modelo de decisão.

(2) Total de ganhos ou perdas proporcionado pelos ativos num dado intervalo de tempo. 